\title{
The Power of the New Microcomputers: Challenge and Opportunity
}

\section{Eric Rumsey}

In the next few years the power and usability of the microcomputer will increase immensely. Current developments that are contributing to this growth are CD-ROM, the 80386 microprocessor, and the graphic user interface. As the information-handling capability of the computer grows with these new developments, the microcomputer industry will increasingly market information products to end users. As this happens, the library will be challenged to provide users the same ease of access to information that they have on their own computers.

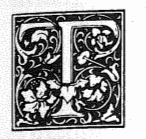

he role of the library is changing rapidly in the kaleidoscopic world of contemporary information access. Computers are altering the flow of information, changing the way old services are performed, and creating totally new services. Commercial vendors are challenging the role of the library on many fronts, including online searching, document delivery, electronic publishing, acquisitions, and userfriendly access to books. ${ }^{1-4}$ And on campus, with the increasing computerization of information, the library will likely take on characteristics of the computer center if it is to survive. ${ }^{5,6}$

Underlying these rapid changes in the information environment is the astonishing growth in the power of microcomputer hardware and user-friendliness of microcomputer software. In three to five years microcomputers will have the power of today's minicomputers and even mainframes, without the accompanying difficulties of these larger systems. Allen Veaner has noted the accelerating growth in microcomputer power and usability:
Mysteriousness and inconvenience, once the hallmarks of the computer, have been almost completely eliminated . . . computers and software are gradually giving users greater and greater power to cut through bureaucracy, formality, and red tape, to extract what they want from data files and information systems. ${ }^{7}$

Veaner also points out the threat to traditional libraries posed by the power of the microcomputer. He contrasts the oftennoted user-unfriendliness of traditional libraries with the new user-friendliness of the microcomputer. ${ }^{8}$ Young faculty and students who have extensive experience with the new powerful, user-friendly computers will bring pressure on the library to provide information in a form as easy to use as it is on their microcomputer. If we fail to do this, he says, other agencies, on campus and off campus, will take over our role. ${ }^{9}$ He notes that just as publishers have learned to bypass the library and market textbooks directly to faculty, information providers will likely also bypass the library in marketing electronic information products to end users. ${ }^{10}$

This paper will show how recent hard- 
ware and software developments are rapidly making the bureaucracy-fighting, user-friendly microcomputers described by Veaner into true information workstations that will give users the power to manage huge data files themselves. These microcomputer developments are CDROM, the 80386 microprocessor, and the graphic user interface. In the course of discussing these advances, the paper will suggest that the microcomputerinformation industry is coming to realize that information handling in the near future will be closely allied to microcomputer use and that the industry will therefore be in the business of selling information products as much as computers.

\section{CD-ROM}

CD-ROM is clearly the first giant step in transforming the microcomputer into a bona fide personal information workstation. Jim Wavada, in accord with Veaner, warns us that CD-ROM should be seen as "the harbinger of the personal research library," which will make it possible for end users to manage their information independently of the traditional library. ${ }^{11}$ He says that although in its early stages CD-ROM is being marketed to libraries because librarians are already familiar with computer literature search techniques, it will be sold mainly to end-users once it becomes established (a view shared by Harold Shill ${ }^{12}$ ). Wavada states clearly the threat posed for the library by CD-ROM:

In [the] coming era, libraries will confront competition from creative entrepreneurs promising personalized research libraries that no longer require the one-to-one contact that has kept the information professional at the center of the informing process. ${ }^{13}$

Evidence confirms Wavada's prediction that CD-ROM will be aimed at the general information user, and particularly the user of microcomputers. One indication is the pattern of reporting of new developments in CD-ROM. The library literature has published a fair amount on CD-ROM in the last two to three years, but it cannot rival the coverage in the microcomputer literature. With at least three weeklies and numerous monthly journals, which are heavily supported by advertising revenue, the microcomputer literature has now become the place to find the most thorough and timely coverage of new CDROM developments. ${ }^{14}$ Another indication of the growing interest in CD-ROM within the microcomputer industry is the attention given the medium by Microsoft. This software company has sponsored four annual conferences on CD-ROM and has lent its support in several other ways also. ${ }^{15}$ Finally, it is notable that the user interface of CD-ROM systems frequently borrows heavily from the interface used in other microcomputer applications. Although this may seem insignificant, it is important because it will make it easier for the general microcomputer user to learn to use CD-ROM.

\section{THE 80386 MICROPROCESSOR}

In April 1987 IBM announced a new line of microcomputers, the PS-2, some models of which are based on the 80386 (generally shorted to 386) microprocessor. There has been some confusion about the nature of these new machines, in large part because there is not yet an operating system to take advantage of the great power of the 386 processor. ${ }^{16}$ But once an operating system is developed and adopted as a standard, the power of the 386 machines will far surpass the DOSbased IBM-PC. Indeed, they will come close to the power level of current minicomputers and mainframes and will certainly have profound effects on all aspects of microcomputing. ${ }^{17}$ Of particular significance for information handling, they will revolutionize database software, making it practical to maintain files approaching the size of CD-ROM databases. ${ }^{18}$ Software enhancements made possible by the power of the 386 processor will make database systems much easier to use. Artificial intelligence features, for example, will make searching databases easier, and hypertext features will make it easy to customize the database interface to the needs of specific users. ${ }^{19,20}$ Much more could be said about the 386 processor and the effect it will have on microcomputing. Whole 
new categories of software are likely to evolve to take advantage of the great power of the 386 processor. The $386 \mathrm{ma}-$ chines will certainly accelerate the trend that has emerged with CD-ROM for the microcomputer-information industry to market products directly to end users.

\section{THE GRAPHIC USER INTERFACE}

As anyone knows who follows the current microcomputer scene, the name of today's user-friendly microcomputer is Macintosh. With its icon-based graphic user interface, the Mac has garnered the image of "the people's computer." Indeed, Veaner's description of the allpowerful computer that allows users to "cut through bureaucracy, formality, and red tape" almost sounds like it is right out of an advertisement for the Mac. But the user-friendliness of the Macintosh is much more than mere advertising hype. The Mac truly is popular, as anyone can easily see by walking into the public microcomputer cluster in our library and comparing the number of students using Macintoshes and IBM PCs.

\section{"Veaner's description of the all- powerful computer that allows users to 'cut through bureaucracy, formal- ity, and red tape' almost sounds like it is right out of an advertisement for the Mac."}

Despite its popularity, the Macintosh has not affected us much in the library. It has been mainly a graphics machine and has not tried to compete with the IBM PC as a text-based workhorse. In the library, we deal mainly with text, of course, so the IBM has suited us well. But the dichotomy between the graphic Macintosh and the text-based IBM is breaking down. The IBM side of the microcomputer industry has seen what an extraordinary success the Macintosh graphic interface has been, and the new 386 machines will therefore have a similar (though as yet undetermined) graphic interface, ${ }^{21}$ thus transfer- ring to microcomputers in general the image earned by the Mac as the user-friendly computer par excellence. Seen from this perspective, a recent ad for the Macintosh appears especially ominous. In a 1987 issue of Newsweek on Campus magazine, hiding in the midst of a verbose sales pitch for the Mac that lists its many virtues for the busy college student is the phrase "There's also software that can tie you into a wide variety of databases . . . so you can check out of the library for good" (emphases added). ${ }^{22}$ At the time this ad appeared, we may have thought we could dismiss its thinly veiled attack on the library as a sales pitch for one particular computer. But just as the microcomputer industry is borrowing the idea of the graphic interface from the Macintosh, it will undoubtedly also latch on to Apple's marketing strategy for the Mac, featuring prominently the information independence made possible by the new computers. This is not to suggest that manufacturers will explicitly mention the library in their marketing campaigns; indeed they are probably not thinking much about us at all. However, the selling of the new computers may contribute significantly to the emerging information matrix that is moving users toward managing their information independently of libraries, and this can indeed be thought of as drawing them in the direction of "checking out of the library for good."

\section{CONCLUSION}

Veaner's prediction of the powerful, user-friendly microcomputer is fast becoming a reality. With CD-ROM, the microcomputer industry has discovered the information market, and it will certainly continue to mine this rich vein when the 386 processor and the graphic interface give users even more informationhandling power. Though this paper discussed new microcomputer developments separately, in reality all of them will work together. When fully equipped 386 computers become available, for instance, their powerful features will be used in combination with CD-ROM. The graphic user interface will be an especially potent addition to the mixture. It will bring the masses to information handling just as the 
Macintosh has brought the masses to microcomputing. CD-ROM and the 386 processor will give users the power to become information independent, but it is the graphic user interface that will harness the power, making the personal information workstation a reality.

\section{"Instead of perfecting our individual question-answering skills, we need to spend our time and energy design- ing computer systems to help us in- terpret the library to users."}

Where does all of this leave us in the library? How can we meet the challenge of the new information environment? The answer is apparent. As Veaner and others have said, we need to learn to combine the unique organizational skills we have as librarians with the vast power of the computer to forge a new role. ${ }^{23,24}$ Evelyn $\mathrm{H}$.
Daniel put her finger on our new mission in a recent forum on reference service when she suggested that instead of perfecting our individual question-answering skills, we need to spend our time and energy designing computer systems to help us interpret the library to users. ${ }^{25}$ There are certainly signs that we are getting the message and using the new power of the microcomputer. ${ }^{26}$ But we must accelerate our efforts if we are to survive. Particularly with the advent of the graphic interface, we need to learn about the power of computer interfaces. ${ }^{27}$ Systems such as Hypercard, for instance, offer a gold mine of interface tools; Hypercard is particularly notable for us because its card metaphor is so much like our old friend the card cata$\log .^{28}$

Summing up, I think we should see the powerful computers of the future not as a threat, but as a great opportunity. As Robert Newhard says, our great challenge is to lead users through the complex new world of information to a higher level, the knowledge level. $^{29}$

\section{REFERENCES AND NOTES}

1. Sue Kennedy, "The Role of Commercial Document Delivery Services in Interlibrary Loan," Interlending and Document Supply 15:67-73(Jan. 1987); Susan B. Ardis and Karen S. Croneis, "Document Delivery, Cost Containment, and Serial Ownership," College \& Research Libraries News 48:624-27 (Nov. 1987).

2. B. Zoellick, "Changing the Publishing Paradigm," in CD-ROM: Optical Publishing, ed. S. Ropeiquet (Redmond, Wash.: Microsoft Press, 1987), p.1-7.

3. Scott R. Bullard, "Acquisitions: Ache and Its Relief: An Acquisitions Specialist Spells Out Remedies for His Harassed Colleagues," American Libraries 18:857-60 (Nov. 1987).

4. Nancy Melin Nelson, “Do You Have Any Good Books About . . .? Information Today 4, No. 10:13, 26 (Nov. 1987).

5. Richard M. Dougherty, "Libraries and Computing Centers: A Blueprint for Collaboration," College $\mathcal{E}$ Research Libraries 48:289-96 (July 1987).

6. Timothy Weiskel, "Libraries as Life-Systems: Information, Entropy, and Coevolution on Campus," College \& Research Libraries 47:545-63 (Nov. 1986).

7. Allen B. Veaner, "1985 to 1995: the Next Decade in Academic Librarianship, Part 1," College \& Research Libraries 46:221-22 (May 1985).

8. Constance A. Mellon, "Library Anxiety," College \& Research Libraries 47:160-65 (Mar. 1986).

9. Veaner, "1985 to 1995: the Next Decade," p.222.

10. Ibid., p.219-20.

11. Jim Wavada, CD-ROM and Libraries: There's Time to Plan: A Special Report to the Fred Meyer Charitable Trust (Portland, Ore.: Library and Information Resources for the Northwest, 1986), p.8; parts of the report appeared in CLASSONLINE 9, no. 7:2-3 (Apr. 1987).

12. Harold B. Shill, "Bibliographic Instruction: Planning for the Electronic Environment," College $\mathcal{E}$ Research Libraries 48:437 (Sept. 1987).

13. Wavada, CD-ROM and Libraries, p.9.

14. See, for example, Daniel J. Rosenbaum, "Faster than a Speeding Librarian," Publish! 3 No.4:77 (Apr. 1988); Barbara Robertson, “CD-ROM: A Young Technology with a Bright Future," Lotus 4, 
No.5:16-18 (May 1988); Jon Zilber, “Optical Horizons: With CD-ROM and WORM Drives, Brave New Worlds of Mega-Information Await," MacUser 4, No.6:157-65 (June 1988); John Rizzo, "Eyeing the Optical Disk Market," Macintosh Today 2:20, 22 (Apr. 19, 1988); and Susan Janus, "CDROM Applications Are Expected to Target More General PC Audience, " PC Week 10, No.6:141-42 (Nov. 24, 1987).

15. Julie B. Schwerin, "Profile-Microsoft and CD-ROM," Electronic and Optical Publishing Review 7, No.1:22-25 (Mar. 1987); Sarah Glazer, "Microsoft: Ushering in the CD-ROM Era," High Technology 6, No.11:14-15 (Nov. 1986).

16. Karl Beiser, "Microcomputing," Wilson Library Bulletin 62:70-71 (Mar. 1988).

17. Nancy Melin Nelson, "Cutting Edge," Wilson Library Bulletin 62:66-67 (May 1988); Mark Brownstein, "To Boldly Go Where No PC Has Gone Before . . .," Info World 10, No.6:21-22 (Feb. 8, 1988); James R. Wruck and R. Scott Cowdrey, "The PS/2 Series in Academia," Academic Computing 2:205-21 (Dec. 1987/Jan. 1988).

18. Jon Pepper, "Powerful DBMS's May Fuel Migration to OS/2," PC Week 5, No.17:99-100 (Apr. 26, 1988).

19. Rick Vizachero, "Access Is Key to Information Overload," Government Computer News 6, No.16:28 (Aug. 14, 1987).

20. Henry Bortman, "The Hypercard Workstation," MacUser 4, No.6:79-80 (June 1988); Laurie Flynn, "More Firms Using Hypercard for Training as a Front End," InfoWorld (Target Edition: Macintosh) 10, No.15:S6 (Apr. 11, 1988); Robert Snowden Jones, "Firms Put Technology to Work as Front End," InfoWorld 10, No.3:29 (Jan. 18, 1988).

21. Will Fastie, "Year of the User Interface," PC Tech Journal 6, No.6:25-29 (June 1988); Jenny McCune, "Unix Gets Graphics Interface that Kicks Off Desktop Battle; Open Look Faces Off against OS-2 and Presentation Manager," Computer System News, No. 362:3-4 (Apr. 18, 1988); Kristina B. Sullivan, "Graphics Capabilities Are PS-2's Strongest Sult, Analysts Say," PC Week 4, No.18:103 (May5, 1987); Preston Gralla, "PC Users Can Expect an Increase of Mac-Level Graphics Programs Soon," PC Week 4, No.32:108-9 (Aug. 11, 1987); Ric Ford and Rick LePage, "MacInTouch," MacWeek 2, No.7:12 (Feb. 16, 1988).

22. Newsweek on Campus (Feb. 1987), p.1-2.

23. Veaner, "'1985 to 1995: the Next Decade," p.222.

24. Richard M. Dougherty, "Libraries and Computing Centers."

25. Peter Hernon and Charles R. McClure, "Library Reference Service: An Unrecognized Crisis: A Symposium," Journal of Academic Librarianship 13:69-80 (May 1987); quote is from response by Evelyn H. Daniel, p.76-78.

26. Martin Kesselman, "LSM Infomaster: A Hypercard CAI Program on a Macintosh Network," College \& Research Libraries News 49:437-40 (July/Aug. 1988); Karen F. Smith, "Robot at the Reference Desk?"' College \& Research Libraries 47:486-90 (Sept. 1986).

27. Jonathan Littman, "Mac Stars at Interface Conference: Mac Recognized as Standard for Graphical Interfaces at Prestigious Conference," MacWeek 2, No.22:26 (May 31, 1988); Bruce W. Lynch, "Interface Developers Manage to Keep Up with Users' Rising Expectations," 'PC Week 5, No.21:37 (May 24, 1988).

28. Bill Atkinson, "Conversation with Bill Atkinson," in The Complete Hypercard Handbook, Danny Goodman (New York: Bantam, 1987).

29. Robert Newhard, "Converting Information into Knowledge: The Promise of CD-ROM," Wilson Library Bulletin 62:36-38 (Dec. 1987). 